\title{
LIBERTAD DE EXPRESIÓN, PODER POLÍTICO Y PROCESOS INFORMATIVOS: ANÁLISIS HISTÓRICO-CRÍTICO
}

\author{
MANUEL ALCARAZ RAMOS
}

La libertad de expresión ha sido, desde el inicio de la teoría de los Derechos y Libertades fundamentales, uno de los Derechos con un contenido políticamente más destacado. En efecto, su potencialidad no acaba con la salvaguarda de un interés individual sino que su garantía era un requisito ineludible para el funcionamiento democrático. El Derecho Constitucional y la Ciencia Política han tenido, pues, que enfrentarse con la naturaleza, teoría y práctica de la libertad de expresión desde esa doble perspectiva. Sin embargo el manto cobertor de un Derecho tan acrisolado no acaba de dar respuestas definitivas a nuevos fenómenos de la vida política contemporánea, decididamente marcada por el peso de lo comunicacional. Sistematizar las preguntas que este hecho significa y avanzar algunas conclusiones forzosamente provisionales ha sido el hilo conductor que ha guiado la realización de esta Tesis Doctoral.

La Tesis se estructuró en tres grandes bloques. El primero de ellos tiene por título «Sobre la libertad de expresión y la necesidad de expresión» y un carácter marcadamente teorético. En él se intenta una aproximación renovada a la libertad de expresión a partir de la teoría de las necesidades de Marx e interpretada por Heller. Desde esta perspectiva la expresión se conceptúa como una necesidad primaria inherente a la hominización y la libertad de expresión como una «necesidad radical». Deteniéndose luego brevemente en las implicaciones que esta afirmación tiene en el ámbito de las concepciones habermasianas, el Capítulo concluye con el análisis de la mercantilización que de la necesidad de expresión y de información se opera en la sociedad actual. Este hecho no sólo tendrá su importancia econpómica sino que también la tendrá ideológica pues los medios de comunicación educan, en la sociedad de masas, en los usos del mercado.

El segundo Capítulo se titula «De Prometeo a Hal 9000: una aproximación histórica a las relaciones entre la información y el poder». En efecto, en él se pretende hacer una lectura de las ideas y formas políticas desde la perspectiva de la permanente dialéctica entre libertad y censura. No pretende, por tanto, ser una «historia de la libertad de expresión», algo imposible antes de las revoluciones burguesas. En realidad se trata de enfrentarse históricamente al desenvolvimiento de 
la necesidad de expresión definida en el Capítulo I y las diversas reacciones que este hecho provocó en las diferentes estructuras de poder.

El tercer gran bloque es el titulado «Libertad de expresión, comunicación y procesos políticos en el estado democrático del capitalismo tardío» $\mathrm{y}$, en cierto modo, es el punto central de la investigación. Parte el Capítulo de estudiar la evolución de las relaciones entre información y sociedad desde el paradigma liberal hasta la actualidad, con el análisis de fenómenos específicos como la constitucionalización de la libertad de expresión. Llegados al Estado actual se intenta explicar las funciones políticas de la información, sobre todo desde el punto de vista de la legitimación. Se enfrenta luego a la crisis del estado social y las nuevas funciones que este hecho atribuye a la información lo que, por cierto, viene a coincidir con un momento de eclosión tecnológica aplicada a los medios de comunicación.

A partir de ese punto se trata de analizar más pormenorizadamente diversos fenómenos del mundo de la información y de la política, tratando de mostrar como ambos campos interactúan incesantemente. Desde este punto de vista se caracteriza a la información, en la actualidad, como a un elemento cohesionador de los aparatos del Estado y a los medios concretos de comunicación como un aparato del Estado. Finalmente el trabajo concluye con unas reflexiones generales sobre algunos puntos concretos de la incidencia de la comunicación en la práctica democrática señalándose abundantes «zonas de sombra» no reguladas por el Derecho Constitucional y que, sin embargo, inciden poderosamente en la realidad de la representación política. 